Military Technical College Kobry El-Kobbah, Cairo, Egypt

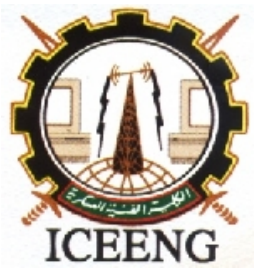

\author{
$8^{\text {th }}$ International Conference \\ on Electrical Engineering \\ ICEENG 2012
}

\title{
Reliability and maintainability analysis of medium voltage transformers in Egypt
}

$$
\text { By }
$$
M. Abdelfatah*
M. EL-Shimy**1
H. M. Ismail**

\section{Abstract:}

In this paper, outage data analysis of $66 \mathrm{kV}$ and $33 \mathrm{kV}$ power transformers is considered. Outage-data is obtained from the Egyptian Electricity Transmission Company. Outage-data analysis over eight years from 2002 to 2009 of 1557 transformers with MVA rating ranging from 10 MVA to 40 MVA is presented. Several indices are determined for evaluating the reliability of power transformers. The knowledge of these indices is essential for proper system planning and operation. Forced outages due to correct and false action of transformer's protection systems are carefully considered. The trend of the determined hazard function indicated that a significant number of the transformers is probably being operated in the wear-out phase; however, detailed ageing analysis is required to determine the reliability state of each transformer. The determined values for the maintainability and availability shows significant variations with time. The results are compared with the IEEE 1979 survey.

\section{Keywords:}

Power transformers; transformer failure; outage data; forced outage; customer interruption.

* Electrical testing and transformers section, EETC. Ministry of Electricity, Cairo, Egypt.

** Electrical Power and Machines Department. Faculty of Engineering, Ain Shams University, Cairo, Egypt. P.O. Box (11517). ${ }^{1}$ Corresponding author: M. ELShimy; email: shimymb@gmail.com, Mob. 01005639589. 


\section{Introduction:}

Based on ANSI/IEEE C57.117-1986 [1], a transformer is a static electric device consisting of a winding or two or more coupled windings, with or without a magnetic core for introducing mutual coupling between electric circuits. The study in this paper considers power transformers for utility applications. For abbreviation, the term "transformers" will refer to "power transformers" in this paper. Transformers are an integral part of power systems, and their reliability directly affects the reliability of the whole network. Outage of transformers is a failure, since a failure is the termination of the ability of a transformer to perform its specified function [1]. Transformer outages are either forced or scheduled. Both types are caused by switching operations. Forced outages of transformers are mainly due to automatic switching operations performed by protection systems [1-3]. They are caused by either external causes (such as transmission line faults) or internal causes (such as core failure and winding failure). More details about failure statistics of transformer subassemblies are available at references $[2,3]$. For an abbreviation in this paper, the term 'outage' refers to 'forced outage'.

In general, there are three distinct phases that a complex product goes through in its life cycle $[1,4,5]$. These phases are infant mortality (or debugging) phase, useful life phase, and wear-out phase. These three characteristics periods are represented by what is called the bathtub curve $[4,5]$.

In this paper, outage data analysis of $66 \mathrm{kV}$ and $33 \mathrm{kV}$ power transformers is considered. Outage-data is obtained from the Egyptian Electricity Transmission Company (EETC), over eight years from 2002 to 2009 of 1557 (average number) transformers with MVA rating ranging from 10 MVA to 40 MVA is presented.

\section{Preparation of Outage Data:}

Outage reports of transformers from 2002 to 2009 are obtained from the EETC. These reports are available only in hardcopy forms and their size is very large (about 4000 pages). The collected data per outage includes the transformer location, date and time, transformer outage duration, protection devices action, transformer restoration (or repair) time, interrupted MW and duration. Data required for conducting detailed ageing analysis could not be obtained.

The installed capacity of the $33 \mathrm{kV}$ transformers in comparison with the $66 \mathrm{kV}$ transformers is very small. In addition, the $33 \mathrm{kV}$ transformers are available only at Middle and Upper Egypt. Therefore, the $33 \mathrm{kV}$ and $66 \mathrm{kV}$ transformers are combined into a single voltage subpopulation, a situation that is accepted and recommended by EETC because both the $66 \mathrm{kV}$ and $33 \mathrm{kV}$ transformers belong to the same dispatching authority. 
The total number of transformers in service was 1379 and 1721 in 2002 and 2009 respectively. Table 1 shows the actual and average numbers of transformers in various geographical zones for years 2002 to 2009.

In Egypt, the 66-33 kV network in the EETC system plays a key role in transferring the bulk power generated to the distribution level. Therefore, reliable performance of the 66-33 kV network guarantees delivery of energy generated to the customers.

There are numerous outage causes for transformers. This is mainly due to operating conditions, aging factor, maintenance strategy, and environmental conditions. According to their type and nature, outage causes are categorized into five outage categories as shown in Table 2. These outage categories are transformer related outages, power system related outages, environmental related outages, human factor (or human mistakes) related outages, and unclassified/other outages [6].

Outage-data analysis is conducted according to two basic phases. Failure and repair analysis of transformers is conducted in the first phase while the impact of transformer outages on customers is assessed in the second phase.

Table (1): Total and average numbers of transformers in various geographical zones for years 2002-2009

\begin{tabular}{|l|c|c|c|c|c|c|c|c|c|}
\hline Zone & $\mathbf{2 0 0 2}$ & $\mathbf{2 0 0 3}$ & $\mathbf{2 0 0 4}$ & $\mathbf{2 0 0 5}$ & $\mathbf{2 0 0 6}$ & $\mathbf{2 0 0 7}$ & $\mathbf{2 0 0 8}$ & $\mathbf{2 0 0 9}$ & Average \\
\hline Cairo & 389 & 405 & 450 & 467 & 486 & 506 & 515 & 528 & 468 \\
\hline Alexandria & 146 & 151 & 155 & 158 & 161 & 163 & 167 & 168 & 159 \\
\hline Canal & 201 & 209 & 218 & 230 & 240 & 244 & 251 & 256 & 231 \\
\hline Delta & 299 & 306 & 318 & 327 & 335 & 344 & 349 & 360 & 330 \\
\hline Middle Egypt & 157 & 160 & 160 & 162 & 163 & 170 & 170 & 179 & 165 \\
\hline Upper Egypt & 187 & 191 & 191 & 197 & 209 & 206 & 220 & 230 & 204 \\
\hline \multicolumn{1}{|c|}{ Total } & 1379 & 1422 & 1492 & 1541 & 1594 & 1633 & 1672 & 1721 & 1557 \\
\hline
\end{tabular}

\section{Outage-Data Analysis:}

\subsection{Failure and repair analysis:}

The distribution of failure numbers per outage cause for the transformers is shown in Fig. 1. For a given outage cause, the percentage number of failures is calculated by 
where $\% A A N F$ is the percentage average number of failures per an outage cause; $N F$ is the average number of failures in the study period per outage cause and $T N F$ is the total number of failures in the study period.

It is depicted from Fig. 1 that the major cause of outages is the outage of incomers (about $40 \%$ ) followed by over current protection (about 29\%) and differential protection (about $5 \%$.

Table (2): Outage categories and corresponding outage causes for the transformers

\begin{tabular}{|l|l|}
\hline \multicolumn{1}{|c|}{ Outage categories } & \multicolumn{1}{c|}{ Outage causes } \\
\hline \hline $\begin{array}{l}\text { Transformer related outage } \\
\text { category }\end{array}$ & - Buchholz and Pressure relief (B\&P) \\
- Over current Protection (OC) \\
- Earth Fault Protection (EFP) \\
- Bifferential Protection (DP) \\
- Freakdown and Damage (B\&D)
\end{tabular}

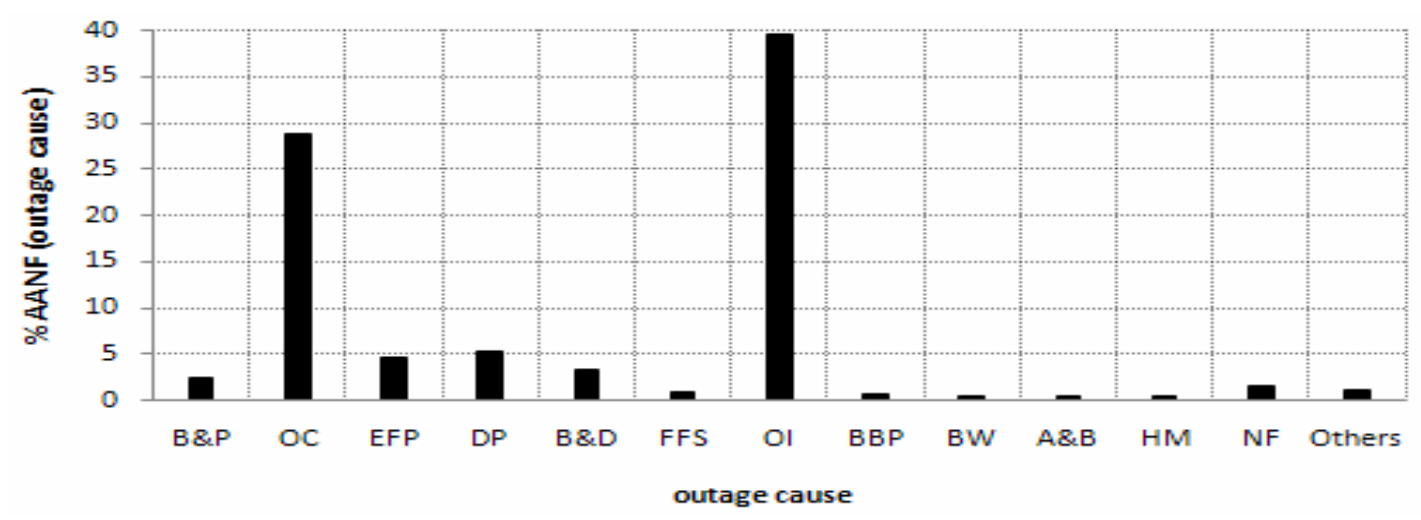

Figure (1): Distribution of failure numbers per outage cause 
The distribution of failure numbers per outage category is shown in Fig. 2. The calculations are done using a modified version of equation (1) such that \%AANF represents the percentage average number of failures per an outage category and $N F$ is the average number of failures in the study period per outage category. It is depicted from Fig. 2 that transformer related outages are responsible for major number of outages followed by the power system related outages and unclassified-other outages. Minor number of outages is associated with environmental related outages and human factor (mistakes).

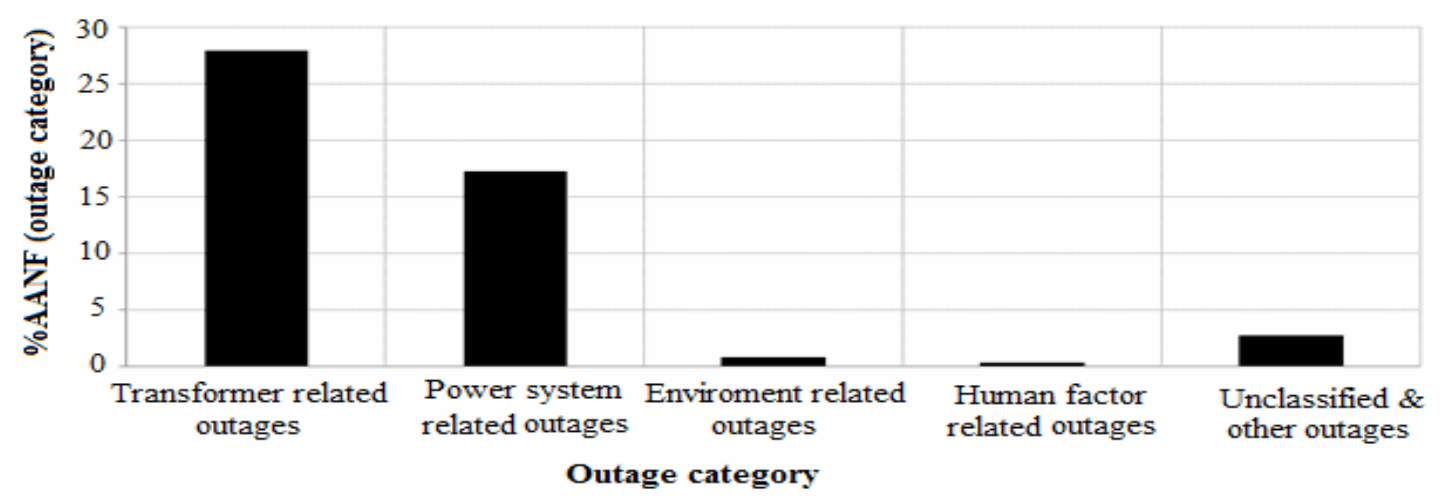

Figure (2): Distribution of failure numbers per outage category

The distribution of failure numbers per outage category per geographical zone is shown in Fig. 3. The calculations are done using a modified version of equation (1) such that $\% A A N F$ represents the percentage average number of failures per outage category in a given geographical zone and $N F$ represent the average number of failures in the study period per geographical zone.

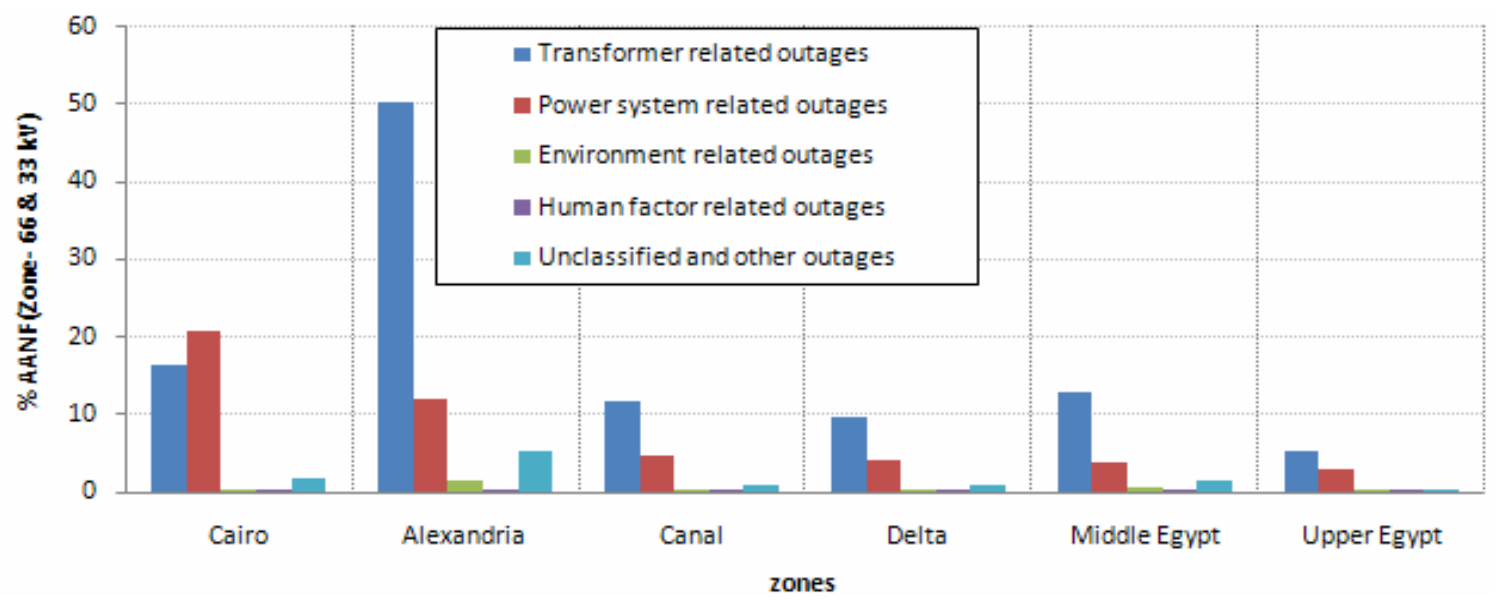

Figure (3): Distribution of failure numbers per outage category for various geographical zones 
It is depicted from Fig. 3 that transformer related outages are the major contributors to the total number of transformer failures in all zones except Cairo zone as a result of power system related outages. However, their major impact is in Alexandria zone where the percentage number of outages due to the transformer related reasons is about $50 \%$ of the overall number of outages. Power system related outages are the main cause of outages in Cairo zone giving about $21 \%$ of the overall number of outages. In addition, their impact is the second for all other zones.

Unplanned outages of power transformers can cost the electric utilities millions of dollars. Consequently, it is important to minimize the frequency and duration of their occurrence. Accordingly, high demands are imposed on the power transformer protective relays that should assure dependability (no missing operations), security (no false trip), and speed of operation (short fault clearing time).

Fig. 4 shows the percentages of false trips of protection devices. The percentage of false trips is calculated as the number of false trips divided by the total number of trips. It is depicted from Fig. 4 that fire fighting systems are the dominant cause of false trips followed by bus bar protection systems. Improper maintenance and monitoring the compressed air line of fire fighting are the main reasons of performance failure of fire fighting protection systems. Lack of maintenance and testing of relays and improper setting of protection devices are the main reasons of poor performance of these systems. Differential protection, Buchholz and pressure relief cause significant number of false outages. Generally, false trips of protection systems can be significantly reduced by improving maintenance procedures, system monitoring, and operation strategies as well as revising the design and settings of protection systems.

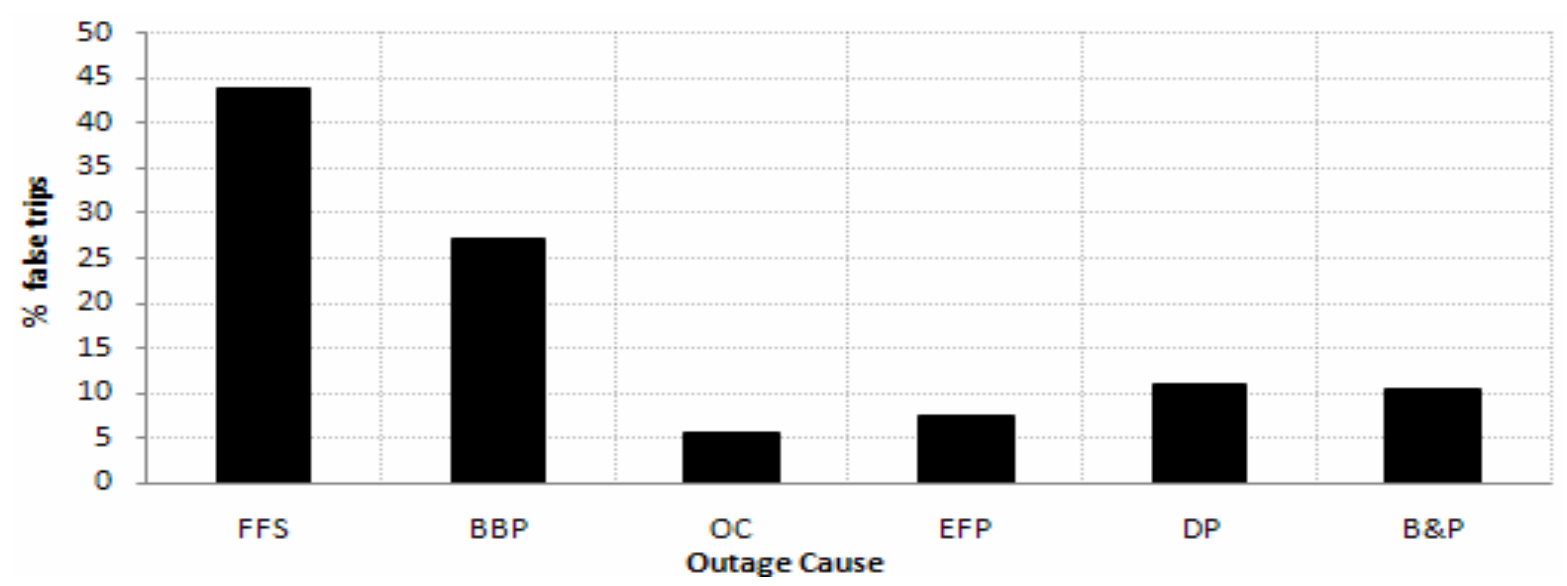

Figure (4): Percentages of false trips of protection devices

The average annual distribution of repair (restoration) time per outage cause is shown in Fig. 5. For a given outage cause, the annual average repair time (AART) per transformer in hours is calculated by 
where $A A R T$ is the annual average repair time per transformer per outage cause in hours; $T R T$ is the total repair time in the study period per an outage cause in hours; $N$ is the average number of transformers in the study period; $T$ is the study period in years.

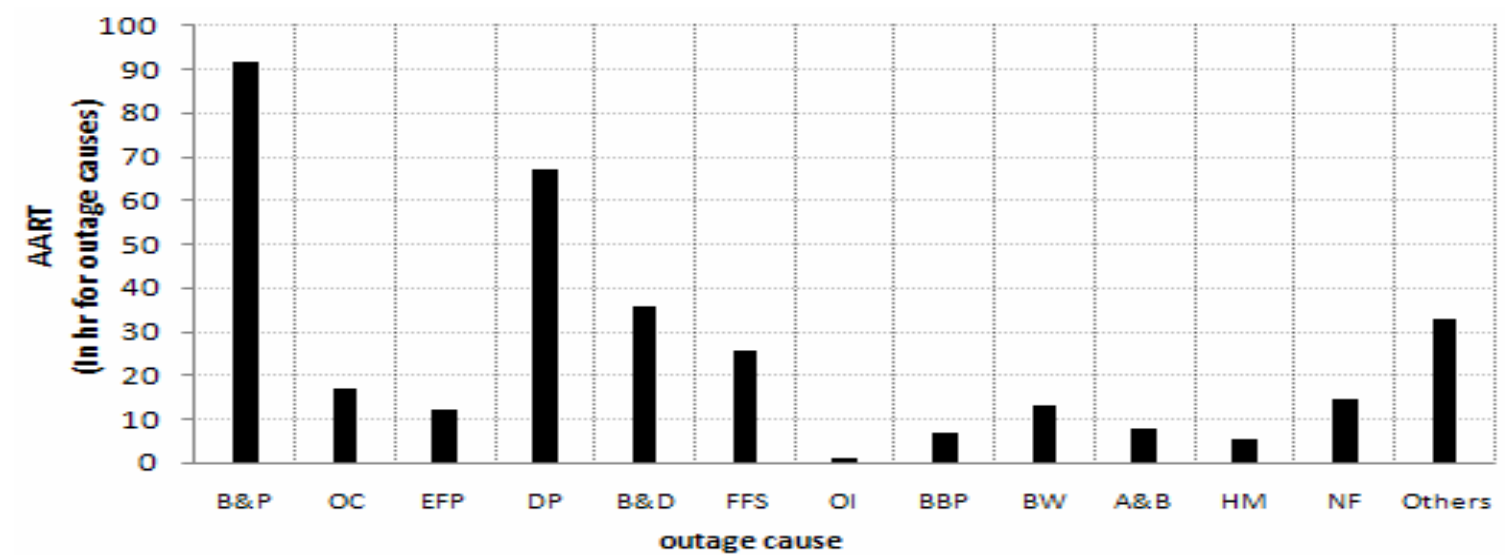

Figure (5): Average annual distribution of repair time per outage cause per transformer

It is depicted from Fig. 5 that among all outage causes, transformer failures that include actions of Buchholz and pressure relief relays take the longest repair time due to severe transformer faults associated with these outages. Differential protection caused the second lengthy repair time because it's associated with an overall routine (site) tests on the transformer and the differential relay. Breakdowns and damages are responsible for the third cause of lengthy repair time to fix or replace the damaged equipment.

The annual average distribution of repair time per outage category per transformer is shown in Fig. 6. The calculations are done using a modified version of equation (2) such that AART is the annual average repair time per transformer per outage category in hours, and TRT is the total repair time in the study period per an outage category in hours. It is depicted from Fig. 6 that the longest annual average repair times are associated with transformer related outages followed by unclassified and other outages.

The average annual distribution of repair time per outage category per geographical zone per transformer is shown in Fig. 7. The calculations are done using a modified version of equation (2) such that AART is the annual average repair time per transformer per outage category per geographical zone in hours. TRT is the total repair time in the study period per an outage category per geographical zone in hours, and $\mathrm{N}$ is the average number of transformers in the study period per geographical zone. It is clear from Fig. 7 that transformer related outages are responsible for long average annual repair time per transformer in all zones. The highest value of average annual repair time occurs in Middle Egypt. Average annual repair times associated with other outage 
categories are insignificant in comparison with that associated with transformer related outages.

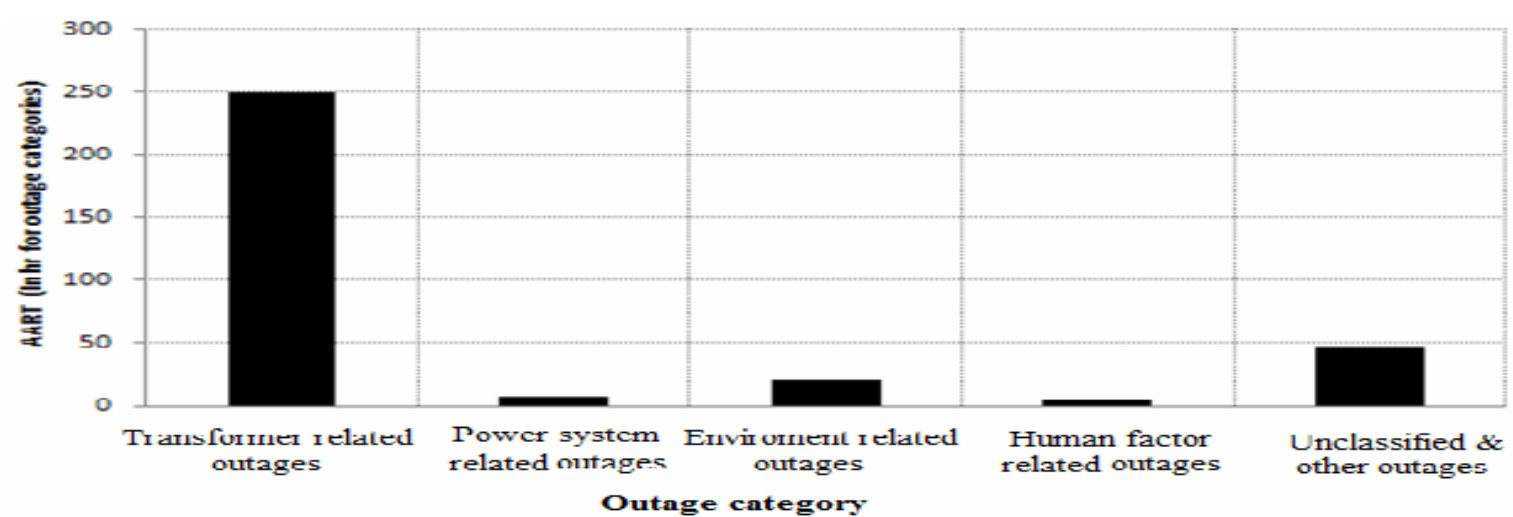

Figure (6): Annual average distribution of repair time per outage category

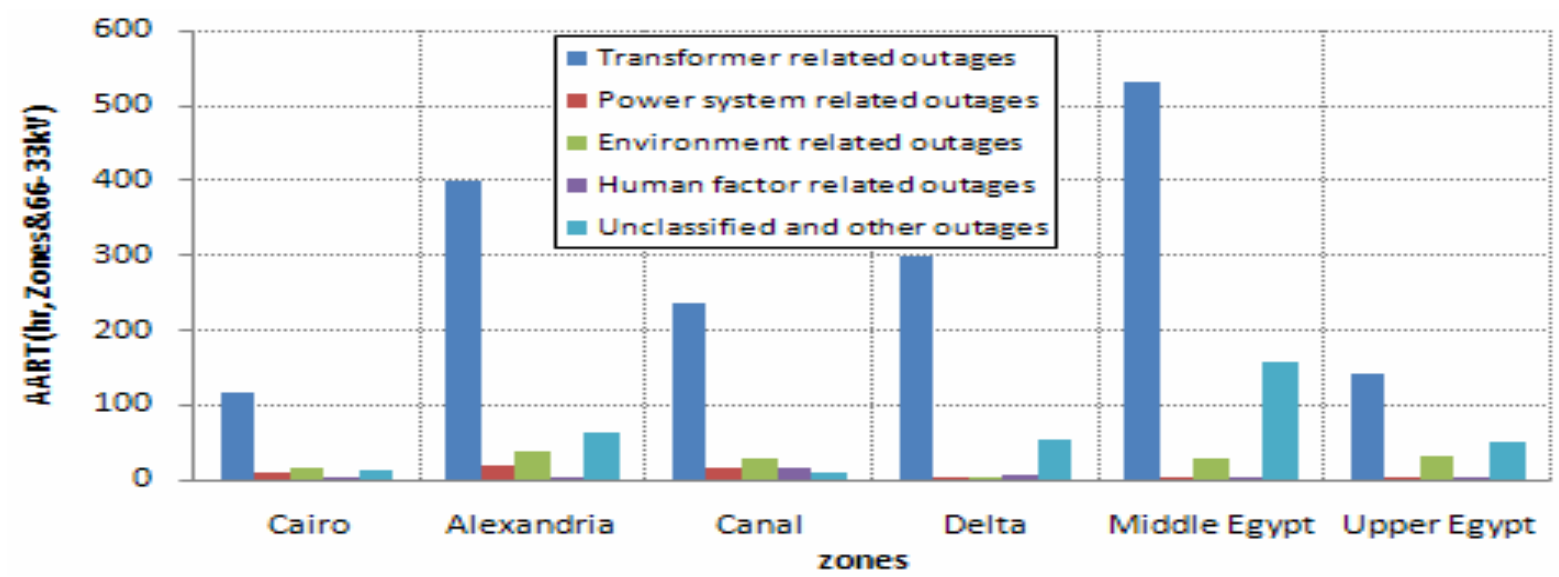

Figure (7): Average annual distribution of repair (restoration) time per outage category per geographical zone

\subsection{Customer interruption analysis:}

Two indictors are used to represent the impact of transformer outages on customer interruptions. These indicators are the annual average interrupted MW (AAIMW) and the annual average customer-interruption duration (AACID). Customer interruption costs can be assessed using these indicators; however, calculation of these costs is retained for future work.

The annual average distribution of customer interrupted MW per outage cause per transformer is shown in Fig. 8. For a given outage cause, the annual average interrupted MW per transformer (AAIMW) is calculated by 
where AAIMW represents the annual average interrupted MW per transformer per outage cause; TIMW is the total interrupted MW in the study period and $N$ is the average number of transformers in the study period.

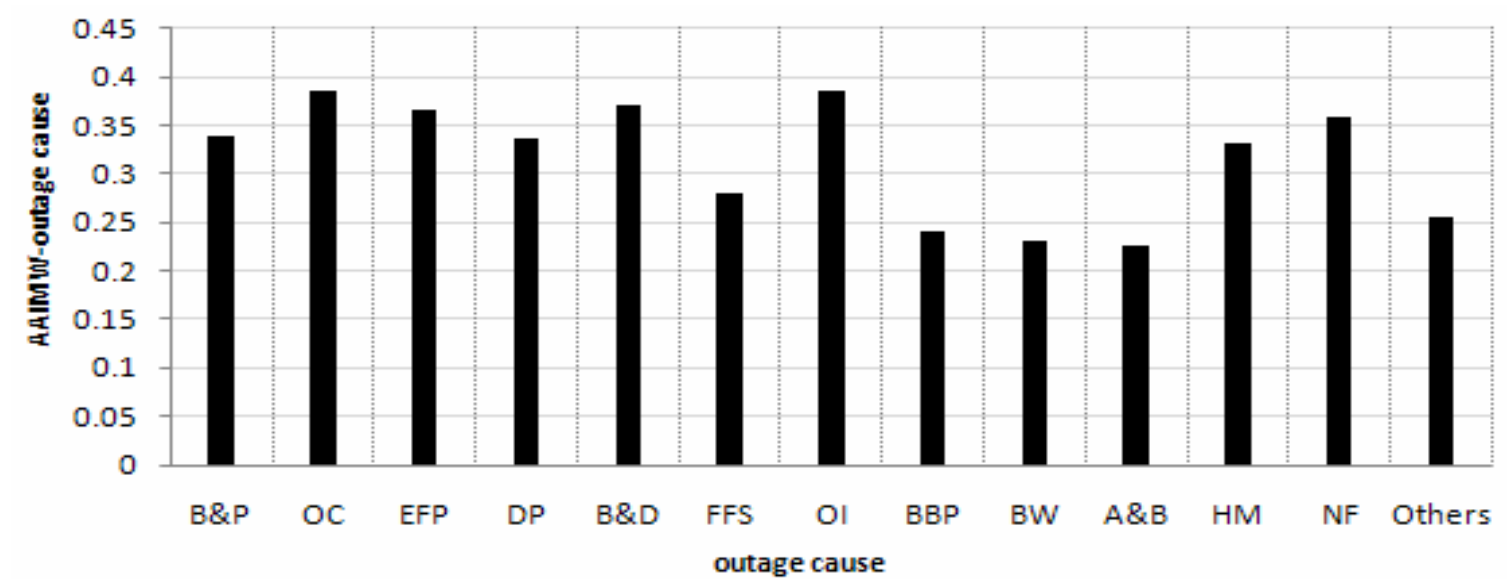

Figure (8): Annual average distribution of customer interrupted MW per outage cause

It is depicted from Fig.8 that the largest values of $A A I M W$ are associated with both outage of incomers and over current protection. Most of these outages occur due to heavy loads and insufficient capacities to face these loads. Furthermore, outages that include breakdown and damage, earth fault protection and no flags caused high values of $A A I M W$.

The AAIMW per outage category is shown in Fig. 9. The calculations are done using a modified version of equation (3) such that $A A I M W$ represents the annual average interrupted MW per transformer per outage category, and TIMW represents the total interrupted MW in the study period per an outage category.

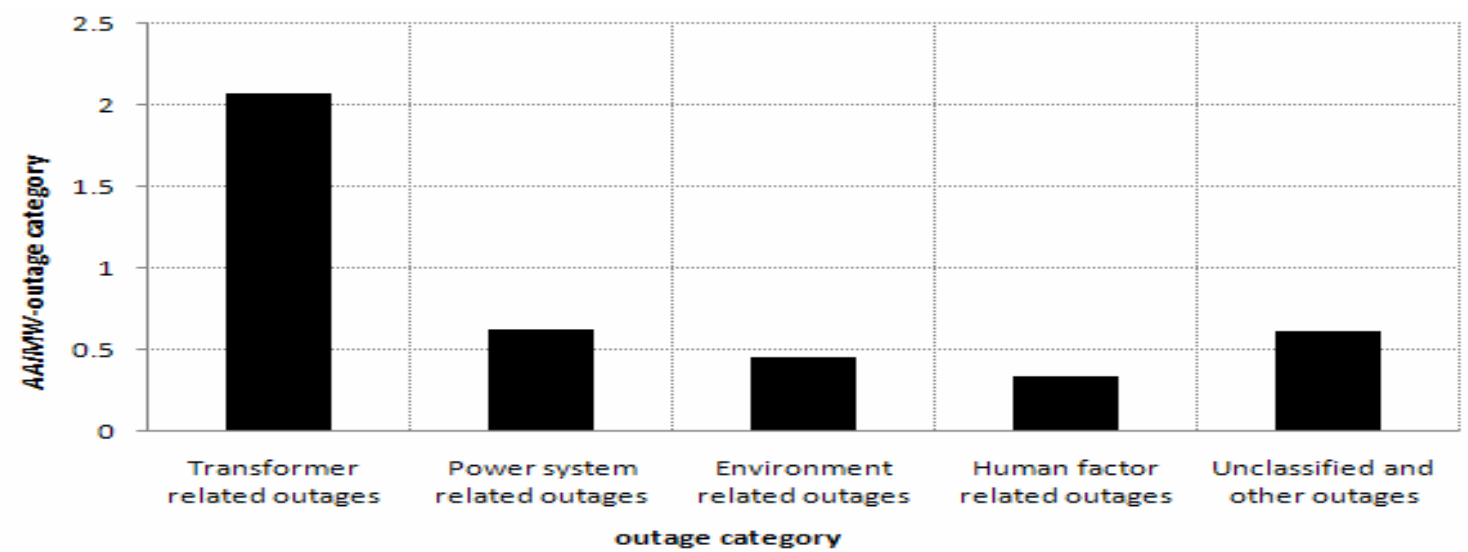

Figure (9): Annual average distribution of customer interrupted MW per outage category 
It is depicted from Fig. 9 that the highest AAIMW is caused by transformer-related outages. Significant values of AAIMW are associated to both unclassified and power system related outages.

The annual average distribution of customer interrupted MW per outage category per geographical zone is shown in Fig. 10. The calculations are done using a modified version of equation (3) such that AAIMW is the annual average interrupted MW per transformer per outage category in a given geographical zone and TIMW is the total interrupted MW in the study period per an outage category in a given geographical zone.

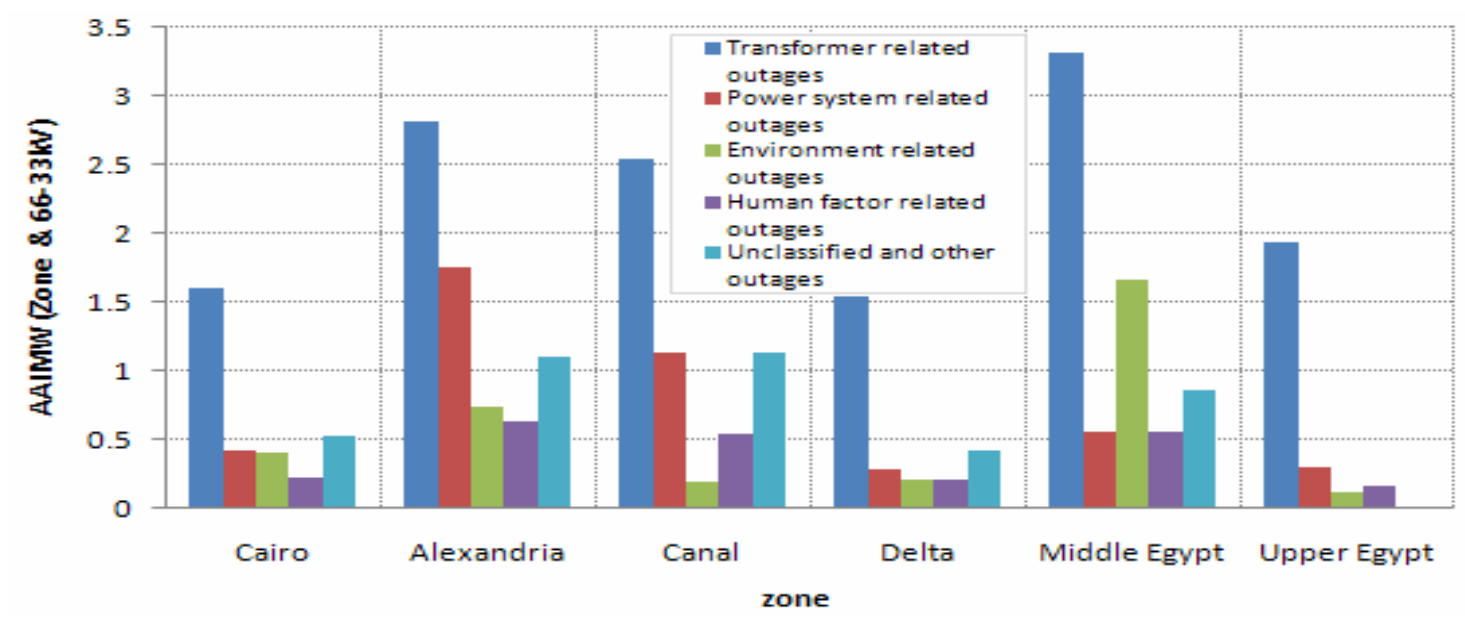

Figure (10): Annual average distribution of customer interrupted MW per outage category for various geographical zones

It is depicted from Fig. 10 that transformer, power system, unclassified and other related outages are the main contributors to the AAIMW. Transformer-related outages cause the highest values of AAIMW in all zones. Unclassified and other related outages are the second cause of AAIMW in Cairo and Delta. Power system related outages are associated with a high contribution of AAIMW in Alexandria and Canal.

The annual average distribution of customer interruption duration per outage cause per transformer is shown in Fig. 11. For a given outage cause, the average annual customer interruption duration per transformer (AACID) in hours is calculated by

$$
A A C I D=T C I D /(N . T)
$$

where $A A C I D$ is the annual average customer-interruption duration per transformer per outage cause; $T C I D$ is the total customer-interruption duration in the study period per an outage cause and $N$ is the average number of transformers in the study period. 


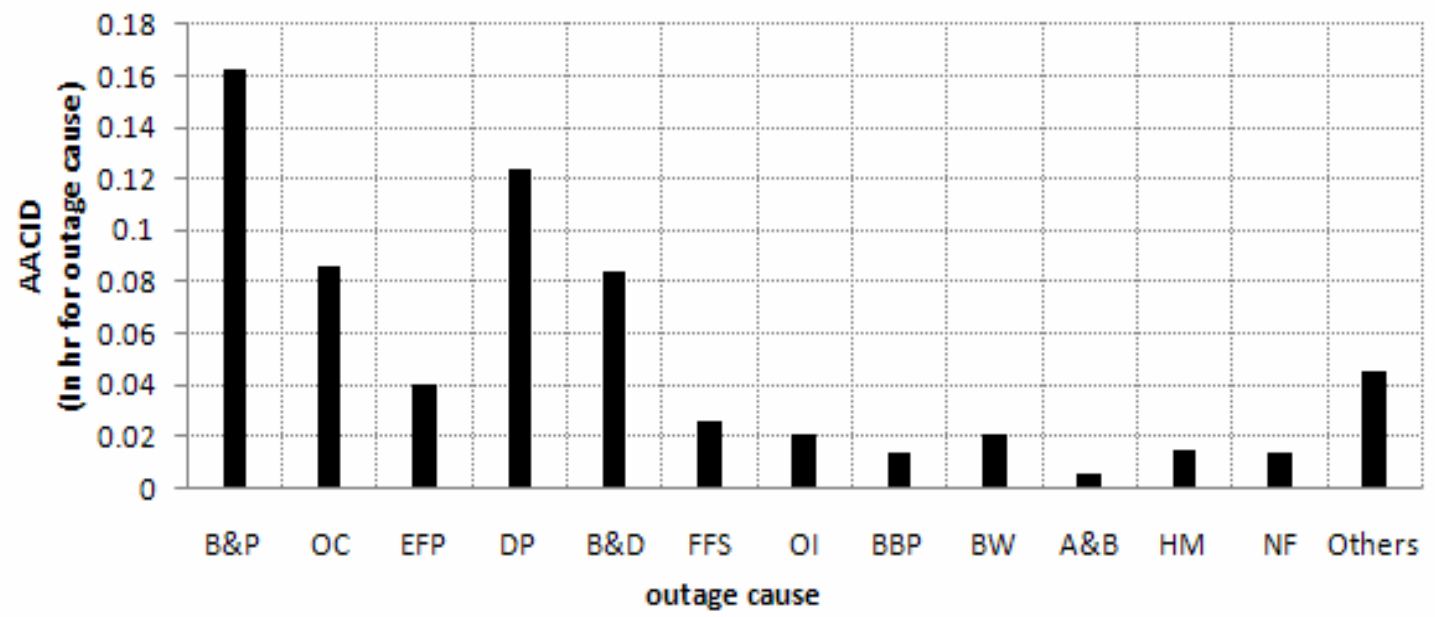

Figure (11): Annual average customer-interruption duration per transformer per outage cause

It can be shown from Fig. 11 that longest AACID occurs due to outages that include Buchholz and pressure relief and differential protection.

The annual average distribution of customer interruption duration per outage category per transformer is shown in Fig.12. The calculations are done using a modified version of equation (4) such that $A A C I D$ is the annual average customer-interruption duration per transformer per outage category, and TCID is the total customerinterruption duration in the study period per an outage category.

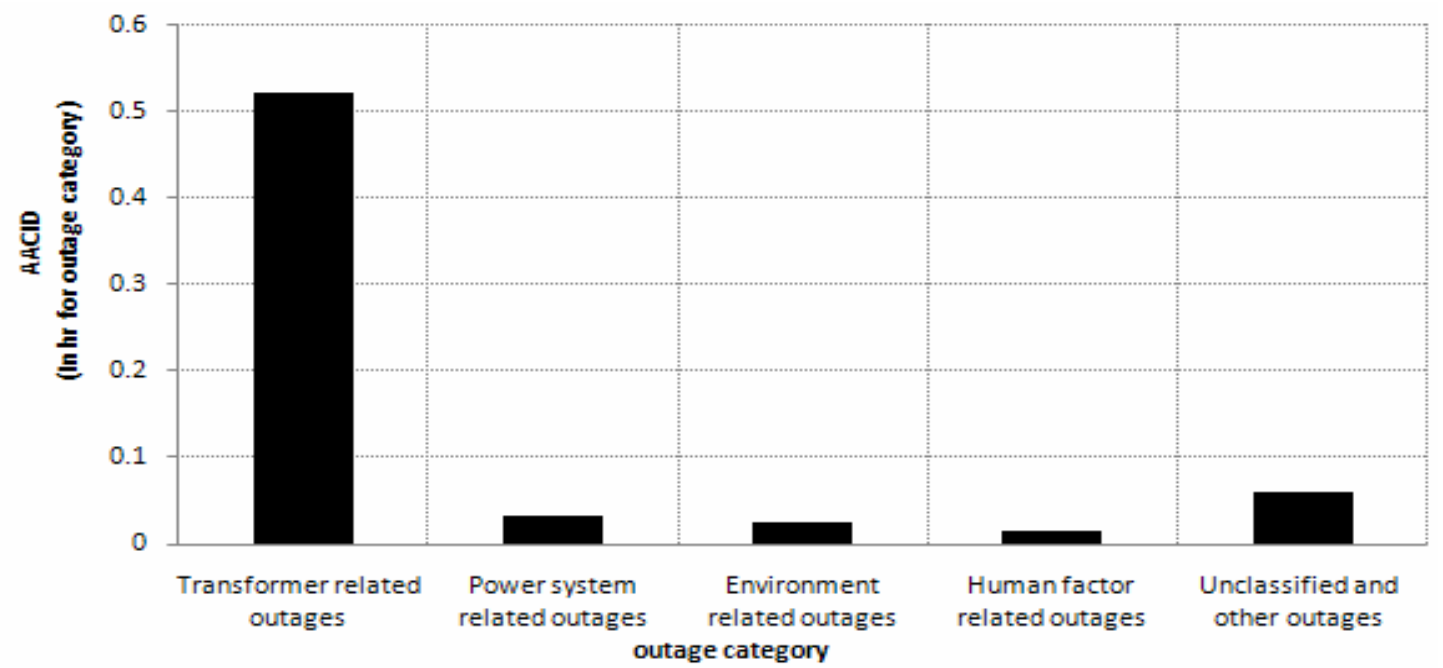

Figure (12): Annual average customer-interruption duration per transformer per outage category 
Fig. 12 clarifies that the longest annual average customer interruption duration is associated with the transformer related outages followed by unclassified and other outages.

The annual average distribution of customer interruption duration per outage category per geographical zone per transformer is shown in Fig. 13. The calculations are done using a modified version of equation (4) such that AACID is the annual average customer-interruption duration per transformer per outage category per geographical zone TCID is the total customer-interruption duration in the study period per an outage category per geographical zone and $\mathrm{N}$ is the average number of transformers in the study period per geographical zone.

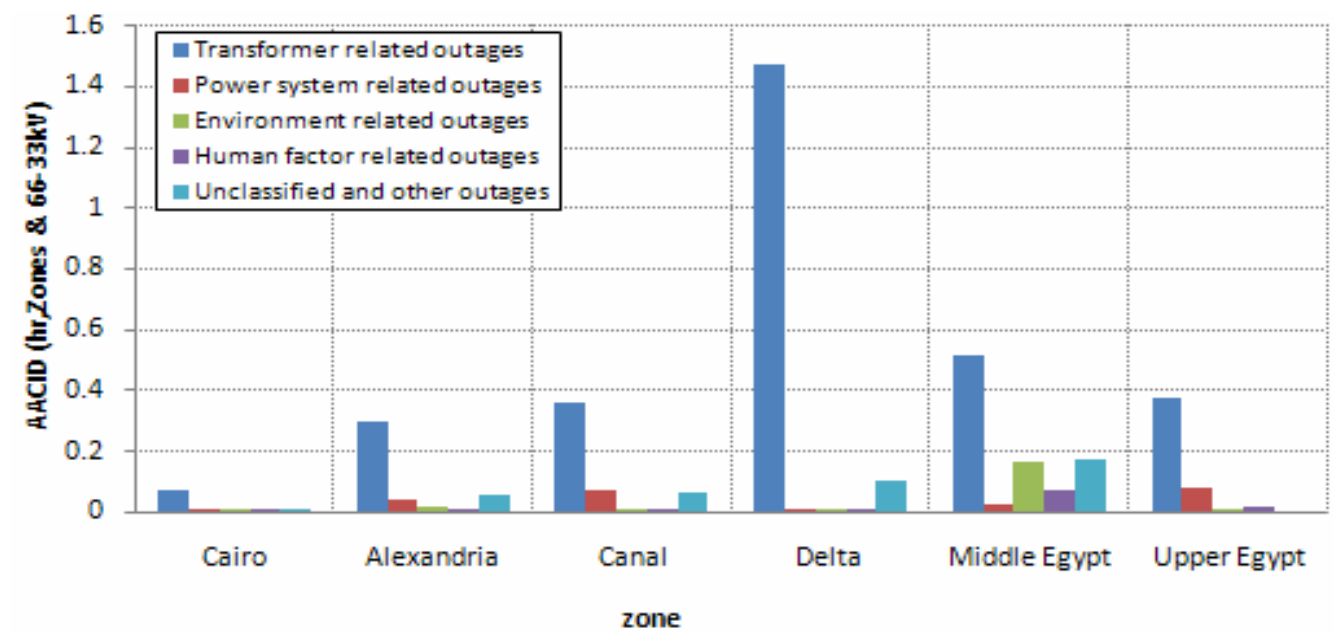

Figure (13): Annual average customer-interruption duration per transformer per outage category per geographical zone

Fig. 13 shows that longest $A A C I D$ occurs in Delta. Transformer-related outages cause the highest values of $A A C I D$ in all zones. Large impact of power system, unclassified and other related outages on the $A A C I D$ is shown in most zones.

\section{Failure rate, Availability, and Maintainability Evaluation:}

Based on reliability theory, the following definitions apply [1,4,7].The failure rate is a measure of the basic design of the transformer as well as the operating and maintenance practices employed. Maintainability is the measure of the ability of an item to be restored or retained in a specified condition. The significant difference between maintainability and maintenance is clarified in $[6,8]$. Availability is the percentage of time the item is available to perform its required functions. Availability is a function of both MTBF and MTTR. 


\subsection{Failure rate:}

During the useful-life phase of a product, the failure rate $(\lambda)$ can be defined as the number of random (unscheduled) occurrences of failure of the product to perform its intended function divided by the length of time the product was functioning $[1,4,7]$. More details of failure rate are mentioned in [6]. In this case, the failure rate (or the hazard function) for this group would be estimated by dividing the total number of failures experienced by the total service years of all transformers in the group as shown in equation (5).

$$
\lambda(t)=T N F(t) /(N(t) \cdot T(t))
$$

In calculating the failure rate, the actual number of transformers for each year in the study period shown in Table 1 is used. Failure rates (or the hazard function) of transformers are shown in Fig. 14.

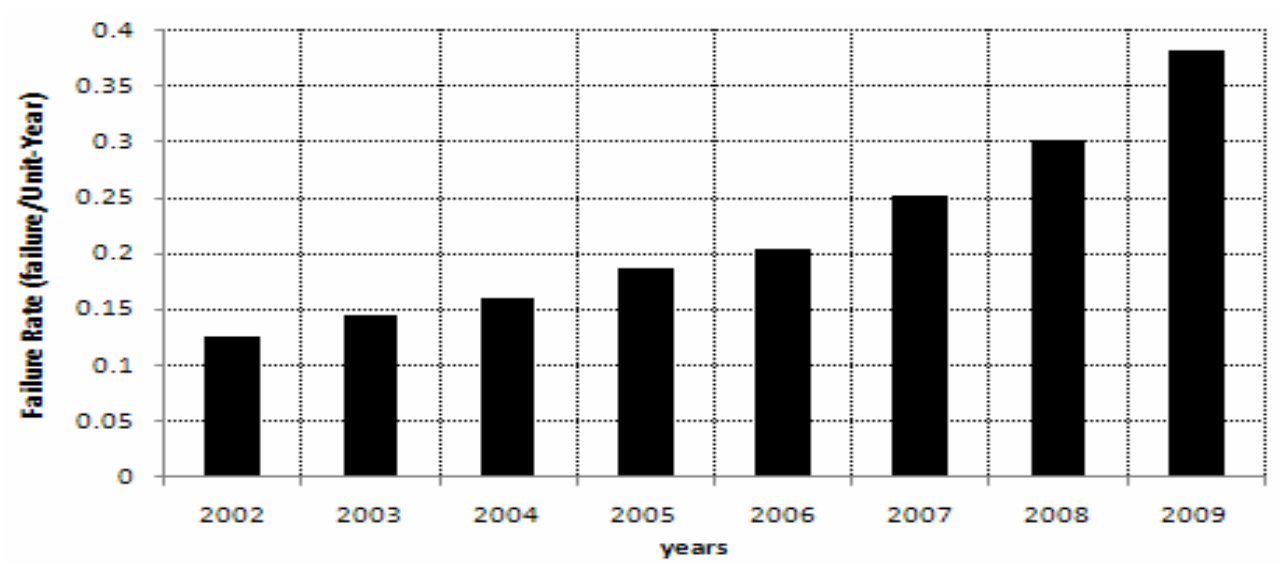

Figure (14): Transformers hazard function

The trend of the determined hazard function shown in Fig. 14 indicated that a significant number of the transformers is probably being operated in the wear-out phase; however, detailed ageing analysis is required to determine the reliability state of each transformer. Therefore, it is recommended to carefully inspect the past failures for each transformer in the considered group in order to define its reliability state. The failure rates values shown in Fig. 14 are compared with the previous IEEE 1979 survey [9]. For convenience, Table 3 shows the results of the IEEE 1979 survey. Based on Fig. 14 and Table 3, it is depicted that the failure rate is very high in comparison with the calculated failure rates in IEEE power transformers survey in 1979. 
Table (3): IEEE power transformers - 1979 survey

\begin{tabular}{|l|c|c|c|}
\hline Equipment subclass & $\begin{array}{l}\text { Failure Rate } \\
\text { ( Failures per } \\
\text { Unit-Year) }\end{array}$ & $\begin{array}{l}\text { Average Repair Time } \\
\text { ( Hours per Failure) }\end{array}$ & $\begin{array}{l}\text { Average Replacement } \\
\text { Time (Hours per failures) }\end{array}$ \\
\hline All Liquid Filled & 0.0062 & 356.1 & 85.1 \\
\hline $\begin{array}{l}\text { Liquid Filled } \\
\text { 300- 10 000 KVA }\end{array}$ & 0.0059 & 297.4 & 79.3 \\
\hline $\begin{array}{l}\text { Liquid Filled } \\
>\text { 10 000 KVA }\end{array}$ & 0.0153 & $1178.5^{*}$ & $192.0^{*}$ \\
\hline
\end{tabular}

*Small sample size; less than eight failures

\subsection{Maintainability Evaluation:}

Maintainability of transformers is shown in Fig. 15. It is depicted from Fig. 15 that the annual values of maintainability are time dependent. Management, human skills, and environmental conditions have their impact on the variation of time required for repairing failures.

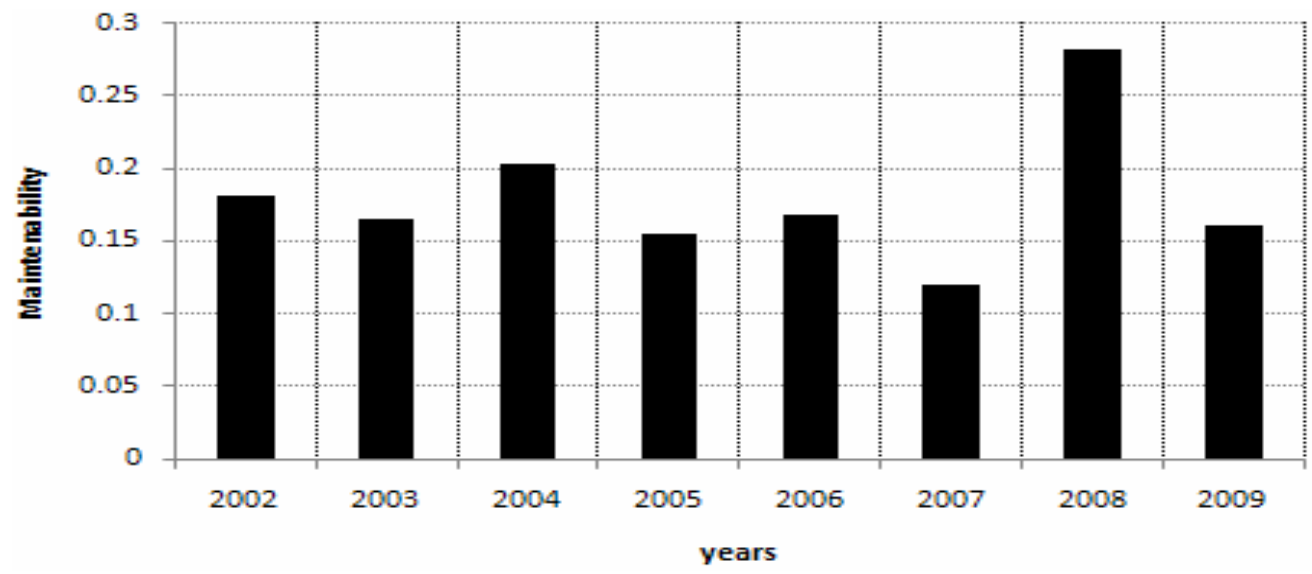

Figure (15): Maintainability trend of transformers (in hours)

The estimated MTTR in comparison with the 1979 IEEE survey Table 3 [9] shows that MTTR of the transformers of the EETC is less than time required for repairing transformers in 1979 IEEE survey.

\subsection{Availability Evaluation:}

The availability is calculated by equation (6) and annual values of transformer availability are shown in Fig. 16. 


$$
A(t)=\operatorname{MTBF}(t) /(M T B F(t)+\operatorname{MTTR}(t))
$$

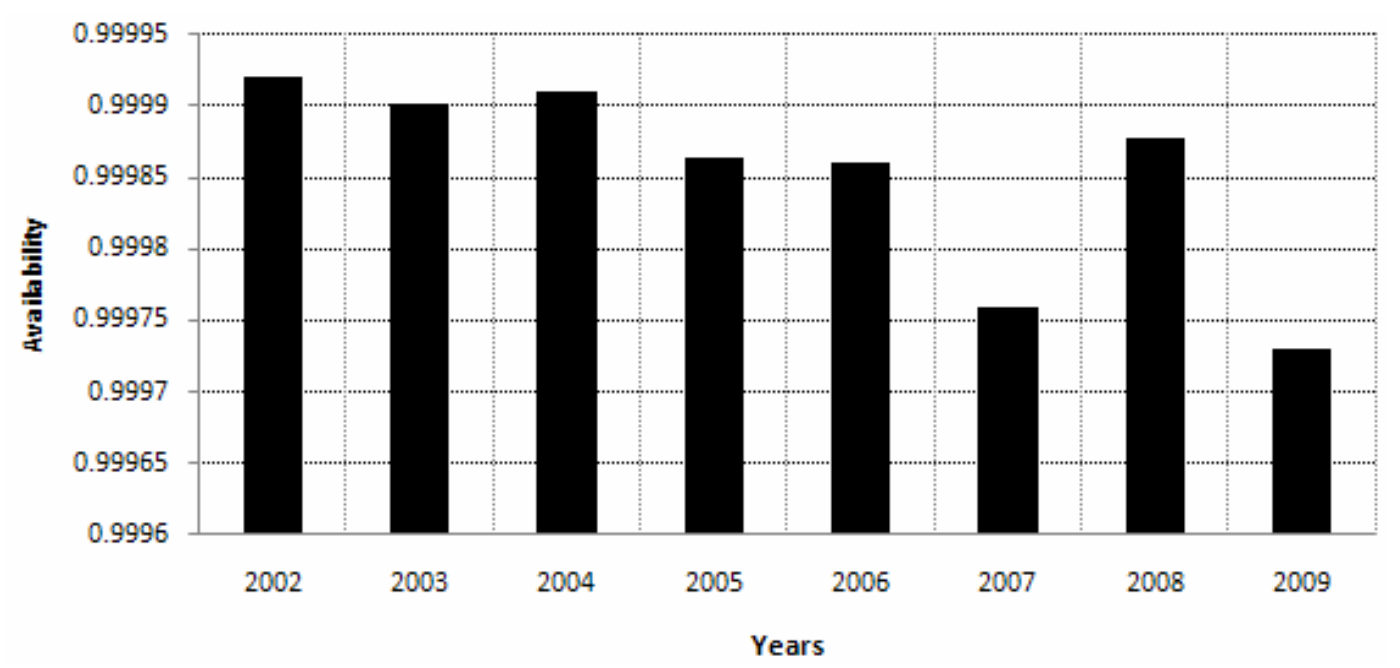

Figure (16): Availability trend of transformers

It is clear from Fig. 16 that the annual values of transformer availability are time dependent. Based on equation (6) and the data shown in Table 3, the average availability is 0.9992 for liquid filled transformers. Therefore, the availabilities of EETC transformers are higher than average availability of the 1979 IEEE survey. Although EETC transformers are having a very high failure rate, their availability is high. This is due to the very small MTTR. Accordingly, the MTTR is considered the most significant factor that can quickly and dramatically have a positive or negative impact on availability.

\section{Conclusion:}

In the $66-33 \mathrm{kV}$ transformers, the largest AANF and AAIMW were caused by outage of incomers and over current protection due to heavy loads. This indicates that the number of $66-33 \mathrm{kV}$ transformers is insufficient to supply the present loads. The longest AACID and AART occurred due to outages that include Buchholz and pressure relief and differential protection as a result of a possible internal failure inside the transformer.

Among all outage categories, transformer related outages recorded the largest AANF and AAIMW in all regions. Furthermore, it caused the longest AART and AACID in all regions

The trend of the determined hazard function indicated that a significant number of the transformers is probably being operated in the wear-out phase. The considered transformers show higher maintainability and availability in comparison with the 1979 IEEE survey. The maintainability and availability vary with respect to time, and its behavior is random. The differences between the estimated values and the IEEE 1979 
survey are caused by many reasons. These reasons are mostly related to local climatic/electrical conditions, logistics management, human skills, and the age of transformers.

It is found by investigation that the poor performance of fire-fighting systems is mainly due to improper maintenance of the compressed air line of these systems. In addition, it is found that lack of maintenance and testing of relays, and improper settings of protection devices are the main reasons of poor performance of bus bar protection systems. Generally, false trips of protection systems can be significantly reduced by improving maintenance procedures, system monitoring, and operation strategies as well as revising the design of protection systems. Therefore, it is recommended to improve the maintenance and design of protection systems especially the fire fighting systems in order to limit the false trips of power transformers.

\section{Acknowledgment:}

The authors would like to express their gratitude to the Egyptian Electricity Transmission Company (EETC) for their valuable discussions, data, and support.

\section{References:}

[1] ANSI/IEEE Std C57.117-1986, IEEE Guide for Reporting Failure Data for Power Transformers and Shunt Reactors on Electric Utility Power Systems, IEEE, 1988.

[2] A. Bossi, J.E. Dind, J.M. Frisson, U. Khoudiakove, H.F. Light, et al, An international survey on failures in large power transformers in service, CIGRÉ Working Group 1205, Electra, P. 21- 48, 1983.

[3] R. Jongen, E. Gulski, P. Morshuis, J. Smit, and A. Janssen, Statistical analysis of power transformer component life time, in: Proceedings of the 8th International Power Engineering Conference (IPEC 2007), Singapore, P. 1273-1277, 2007.

[4] R. Billinton, and R.N. Allan, Reliability evaluation of engineering systems: concepts and techniques, 2nd edition, Springer, 1992.

[5] T. Gönen, Electric Power Distribution Engineering, McGraw-Hill Inc., 1986.

[6] M. Abdelfatah, M. EL-Shimy, and H.M. Ismail, Reliability and Maintainability Analysis of $220 \mathrm{kV}$ Power Transformers in Egypt, Ain Shams Engineering Journal (ASEJ), Vol. 2, P. 183-194, 2011.

[7] Applied R\&M Manual, for Defense Systems (GR-77 Issue 2009). Available at: http://www.sars.org.uk/BOK/, 2009. 
[8] M.J. Smith, Reliability, availability, and maintainability of utility and industrial cogeneration power plants, in: Proceedings of the Industry Applications Society Annual Meeting, P. 1783-1787, 1989.

[9 IEEE STD 493-1990, IEEE Recommended Practice for the Design of Reliable Industrial and Commercial Power Systems, IEEE, 1990.

\section{Biographies}

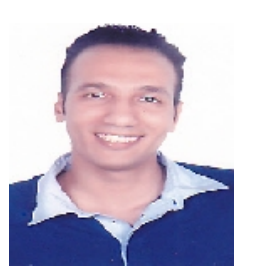

Mohamed Mahmoud Abdelfatah holds a B.Sc. in electric power and machines engineering from Ain Shams University. He is now a M.Sc. candidate at Ain Shams University. Since 2007 until now, he is working as a testing engineer for power transformers in EETC (Cairo zone).

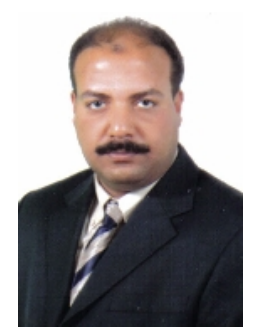

Mohamed EL-Shimy Mahmoud is currently an associate professor in the department of Electric Power and Machines - Faculty of Engineering Ain Shams University. In addition, he is an electromechanical specialist, a freelance trainer and a member of many associations and professional networks. He is also a technical reviewer for some international journals and conferences. His fields of interest include power system analysis, power system economics, power system optimization, electric power distribution, renewable-energy resources and technologies, and power system reliability. For more details, please visit: http://shimymb.tripod.com and http://eg.linkedin.com/in/shimymb Tel.: +2 01005639589. (Corresponding author).

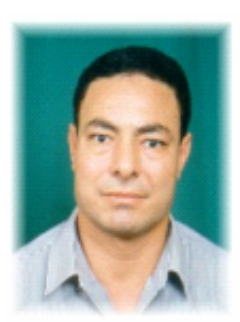

Hanafy Mahmoud Ismail was born in Cairo, Egypt, in 1956. He received the B.S. and M.S. degrees in electrical engineering from Electrical Engineering Department, Faculty of Engineering at Ain-Shams University, Cairo, in 1979 and 1984, respectively. He received the Ph.D. degree in 1989 from Electrical Engineering Department at the University of Windsor, Windsor, ON, Canada. Since graduation, he has been working at the Electrical Engineering Department, Faculty of Engineering, AinShams University. He is now a Professor and deals mainly with the high voltage power transmission and their associated electrostatics and electromagnetic fields. He is also working in the area of power systems, underground cables, and fault detection on transmission lines. 